\title{
Analysis on the Reason of Chinese College Students' Weakening Social Responsibility and Cultivation from Sociological Perspective
}

\author{
Xi Zhang ${ }^{1}$ \\ ${ }^{1}$ College of Politics, Sichuan Agricultural University, Ya'an, China \\ Correspondence: Xi Zhang, College of Politics, Sichuan Agricultural University, Ya'an, Sichuan, China. E-mail: \\ zhangxi2279@163.com
}

Received: January 12, $2012 \quad$ Accepted: February 19, $2012 \quad$ Published: May 1, 2012

doi:10.5539/ass.v8n6p132

URL: http://dx.doi.org/10.5539/ass.v8n6p132

\begin{abstract}
Social responsibility is the ethical care and obligation that individual in society pays to others mentally and sensuously, the ethic responsibility and feeling people have experienced that they should give to the society or others. Contemporary college students are the main force of building a well-off society, a harmonious socialist society in China. Confronting the current situation of some college students' weakening social responsibility and society's higher demand for social responsibility of talents, ideal and faith education needs to be improved to strengthen college student's social responsibility; moral education needs to be strengthened to awake students' ethics responsibility; social practice needs to be improved to reinforce students' social responsibility; comprehensive quality needs to be improved to enhance college students' social responsibility.
\end{abstract}

Keywords: sociology, social responsibility, cultivation, college students

In the current situations of the development of economic globalization and information network, the mutual influence of all kinds of thoughts and cultures throughout the world, and the increasing diversification of social-economic composition, forms of organization, ways of employment, interest relations and forms of distribution in China, the importance of citizens' social responsibility is highlighted at present, and requirements of talents' social responsibility are increasing. College students are precious talents resources of a country, the hope and future of a nation. Meanwhile, they are also the main force of building a well-off society, a harmonious socialist society in China. However, some college students' social responsibility are weakening due to the impact of many factors, which directly influence the ability of college students take the historical duty in the future. Therefore, it is greatly urgent and important to further cultivate and strengthen college students' social responsibility in order to shoulder society-assigned tasks in new period.

\section{Social Responsibility's Connotation and Embodiments of College Students' Weakening Social Responsibility}

Social responsibility is the ethical care and obligation that individual in society pays to others mentally and sensuously, the ethic responsibility and feeling people have experienced that they should pay to the society and others. It specifically embodies socialization of individual thinking, which is expands thinking object from individual to society. It also embodies individual's active and comprehensive participation in social life. Social responsibility has plenty of connotations: it requires a person to have lofty ideals, sound personality; study assiduously, professional dedication, be just and honest, solidify friendly, care about collective, struggle arduously, obey disciplines and laws. Sociology assumes that society is composed of people, and person is the direct agent of social relationship. Composed of individuals, society it is not the simple gathering of individuals, but the mutually related whole of individuals. Specifically, it is impossible for an individual to survive and develop isolatedly and freely without interaction and relation in social system. Therefore, the sense of responsibility an individual pays to society and others is not only the simple need of individual survival and development, but also the need of co-building a harmonious society.

Chinese nation pays great attention to the education of social responsibility, such as these very familiar aphorisms which passed on from generation to generation, "be the first to worry the woes of the people, and the last to share the weal of the people", "everybody is responsible for the rise and fall of the country" etc. All these aphorisms imply sense of social responsibility and ethnic calling in far-sighted scholars. Under the present new 
situation of, the main trend of contemporary college students' social responsibility is upward and positive. However, some college students can't properly realize and shoulder their responsibilities for the country, nation and collective, and show weakening tendencies of social responsibility. These tendencies are mainly reflected in three aspects: firstly, strong self-awareness and weak personal responsibility. Some students are self-centered, uphold the idea of "pursuing self-realization, perfecting self-value". When collective and individual are in contradiction, they only see themselves and are self-centered; when public interest and personal interest are in contradiction, they attach importance to their own interest; they are lack of the spirit to sacrifice for society and collective; the phenomenon of emphasizing material gains, needs, demands without morality, the sublimation of spiritual shackles, and dedication are popular among them. Secondly, devaluing social morality, discipline awareness and role responsibility. Some college students unwillingly study and are tired of learning, and some are just lazing away for the diploma. Therefore, some students cheat in examinations, some ask for better scores from teachers, and there's a good market for "hackers"---substitute examinees. Some students willfully sabotage public properties, let the water faucet open after using, keep the lights on after leaving. Some students even have unacceptable intimacy with partners in public, and culture rubbishes such as "toilet culture" and "desk culture" remain incessant after repeated prohibition. Thirdly, the dislocation of social responsibility and personal responsibility. Some students are so immersed in family care that they can't unify social responsibility and personal responsibility. It turns out that they excessively emphasize their own personality defects, which lead to the parochialism and shortsightedness of youth students' responsibility awareness. They can't rightly distinguish the relation between society and individual.

\section{Analysis of the Reason of contemporary college students' Weakening Social Responsibility}

\subsection{Social Environment Factors}

From the aspect of social environment factors, diversification of society, side effects of market economy, influence of western individual departmentalism and misleading of the modern mass media are the main reasons. Diversification of society makes every organization and everyone pay attention to the realization of their own interests. The whole society's background becomes much more obscure. It causes people to be skeptical of the interest of the society and the society they live. Market economy, which stresses individual interest and highlights the difference among individual interests, easily makes people form the concepts of individual departmentalism, egoism and money worship. The main trend of modern western thoughts is individual departmentalism, which puts individual against society and neglects social interest rather than individual interest. Therefore, this kind of thought doesn't acknowledge that individuals should shoulder the responsibilities for others and society. Modern mass media has problems in recommendation of the value and responsibility of main trend, and phenomenon of unscientific and unhealthy spreading contents in moral publicity and misleading education. All these factors exert adverse influences upon the forming of social responsibility in college students and to some extent, make those students who can't differentiate from right and wrong, confused about the acknowledgement of social responsibility and choice of right behaviors.

\subsection{Social Education Factors}

Social education refers to the education which social life exerts influences on the development of personal mind and body. Countries or regimes which have different social systems implement social education with different natures. From the aspect of social education, there are two main reasons. Firstly, Chinese education has always put much emphasis on the orientation of social value while neglected the development of students' independent personalities. Faults and anomies existed in college students' moral education work mostly owe to insufficient recognition of the fundamental functions of moral education. We always suppose to cultivate some perfect students who are eligible in ideology and morality aspect judged from one social angle, and use some exterior social standards to require and evaluate students' moral activities and their moral aspects. It turns out that abstract responsibility requirements lead to ignorance of fundamental responsibilities of some students, and cause social responsibility's "vacuum state": not qualified to fulfill the big events while reluctant to do the trifles. At the other side, the reason lies in colleges and universities' education management. There are still some problems in ideological and political work, teaching and students management work, which are not good for the cultivation of college students' social responsibility. These problems can lead to the misleading of college students' strong desire in self-perfection and self-development. Realizing their self-perfection and self-development based on individual interest, college students attach much importance to the responsibilities for themselves while neglect the responsibilities for society and collective in the duty performing process.

\subsection{Family Education Factors}

Family education refers to the education parents give to their children in family life. Family education is the 
foundation for school education and social education and also the supplement and stretch for school education. According to the research data, nuclear family is the universal family type in China and takes up $68.15 \%$ in all of the family types. Along with the nuclear family is the only-child's education. According to the incomplete statistics, the ratio of only-child students in college students has reached $76.8 \%$. Only-child college students who have superiority in their grow-up are over-concerned, self-centered and require more from their parents, others and society. They don't require much from themselves; they have strong sense of their rights and weak sense of responsibility. At the same time, contemporary college students don't have much social experience, it makes them have one-sided and partial understanding of the world. They also hold the idea that the purpose of entering college is not for rendering service to repay our motherland and sacrificing to the society, but for obtaining a decent, stable, and salary-satisfying job to fully realize their individual interest. College students' understanding of the society are always limited and hampered by the social phenomenon they focus. They think that the society in which everyone plans for themselves was the real society. They can't recognize the mutual dependence and mutual-shouldering of responsibility between people, person and society, neither can they follow the main trend and development of social life.

\section{Using Ideal and Faith Education as the Core Method to Strengthen College Student's Social Responsibility}

\subsection{Improving Ideal and Faith Education to Strengthen College Student's Social Responsibility}

The social function of education is to help people to be useful in society, which means helping them to cultivate their personality close to social character, and accord their desire with the role. The duty of university education does not just foster talents, but also forms students' social responsibility. The reason of irresponsibility of contemporary college students is lacking of ideal. Ideal is the life goal, which lead people's activity and daily life; ideal should be noble living standard, which regulate people's life and mobilize them away from vulgar taste. Therefore, under the new situation, we must strengthen students' ideal and faith education, help them establish scientific outlook on life and world. Especially, during the process of entering university education and initiate education, we should focus on the education of value and ideal, achieve the transition of their life goals, lead their historic responsibility, and fully convert the educational content into faith and social duty. Besides, correct guidance of students' understanding their relation with society is also an important part of ideal education. Marx believed that only in group people can gain the chance of all-round development, which means only in group, individual can achieve freedom. The relation between individual and society is distinct and linked, coexisted and dialectical united. Individual cannot exist without society, which means the realization of human nature is the summation of every social relationship; meanwhile society doesn't form without individual. No individual, no society. If college students correctly understand the relation between individual with society, they will realize the responsibility is compulsory to fulfill self value, which is the benefit of social responsibility formation.

\subsection{Strengthening Moral Education to Awake Students' Ethics Responsibility}

Daniel Bell, American socialist, stated that every society should set up a system with certain meanings which people can use to demonstrate the collection from themselves to the world. These meanings regulate a set of purpose, like myth or ceremony, explaining the character of common experience, or rebuilding nature through personal magic or technology. The loss of these meanings in these fields would cause a puzzled situation, not affordable, so people are forced to pursuit new meanings to avoid everything left from turning into empty. Strengthening moral education is the best way to turn college students' social responsibility into self-aware behavior. Strengthening moral education can accord the social requirement of ethics with personal needs. Therefore, on one hand, in the process of moral education, we need conquer the situation, of over standardization with less education guidance, excessive legalization but weakening humanistic care. On the other hand, we should awake students' moral responsibility to others, collective and society through ethics education. We have to help students combine their metaphysical pursuit and form pursuit, according to their thought and dream characteristics. We should also help them avoid their inner world collapse or even ideal materialized, improve their conception of happiness and life value, build their respect and reverence to science, truth, democracy, ethics and law, and inspire their life belief and dreams.

\subsection{Improving Social Practice to Reinforce Students' Social Responsibility}

The innate character of human society is achieved through practice, which means understanding of society through practice. The values of college students are formed by social life activities, which also can only be altered by social practice. Social phenomenon is complicated, with true and false parts, positive and negative parts. Because of the limits of life and horizon, students are apt to misunderstand the essence of society and form some wrong conceptions to guide their behavior. Therefore, it's necessary to lead students to understand the right 
national and people's conditions through practice. On the on hand, we can help them collect and conclude the true and dominant values, and grasp the essence and truth of society; we can lead them to realize the reasons of temporary social problems and what our party and country do to solve these problems; we can guide them to step on the height of time and social development in order to strengthen the sense of historical responsibility. On the other hand, through social practice, students can sharpen their will and morals, respect the masses in thoughts, close to public in heart, and obey people in activities; consciously they bond themselves with the broad masses of the people, and sublimate their responsibility. Besides, strengthening social practice can bring them into closer interest relationship with group, improve self-involved consciousness and team spirit, and foster collective spirit and the awareness of responsibility and duty. Only by self understanding of responsibility can students activate interior impetus and further rise to social responsibility consciousness.

\subsection{Improving Comprehensive Quality to Enhance College Students 'Social Responsibility}

Quality is the internalized, personalized and comprehensive result of experience, awareness, ability, wisdom and personalities. Comprehensive qualities directly affect the time, level of students understanding social responsibility, the awareness, emotion and consciousness during the process of forming social responsibility, and the whole moral, political and legal characteristics. The formation of comprehensive quality counts for a long period, we should, as far as we can, involve our students with varied social activities, balance their pursuit of materials and spirits, and accord their personal interests with public and social interests, and put others and social interests first in contradictive situation. The key to improve college students' over-all qualities is to help students to clear their goals and directions, study hard while cultivating fine taste, build their body while fostering excellent psychological diathesis, finally achieve an integrated development. Especially, we need to help them to improve their practical ability, actively participate in social work, learn from public, sharpen will, truly enhance creativity and enterprise competencies, and finally lay a strong foundation for them to enter society and succeed in career. Besides, as a teacher in university, we also need a high level of social responsibility. If teachers firstly set a good example, it will gradually affect students' behavior; conversely, it will draw a negative effect.

\section{Acknowledgements}

This work was supported by the project of Ideological and Political Education Key Research Subject in 2009 of Sichuan Education Ministry, "sticking to the students-oriented aim, innovating ideological and political education in universities and colleges".

\section{References}

Daniel Bell. (1989). Culture Contradiction of Capitalism. Beijing: Sanlian.

Derk Bok. (2001). Beyond the Ivory Tower. Social Responsibility of Modern University. Zhejiang: Zhejiang Education Press.

Lai, Jinlong. (2011). Pondering on the Education of the Sense of Social Responsibility for Contemporary College Students. Journal of Sanming University, 03.

Peng, Wenying. (2008). Argument on the cultivation of college students' social responsibility under harmonious background. Theory Monthly, (01).

Wang, Danling, \& Sun, Lili. (2006). Moral emotion and college students' social responsibility. Heilongjiang Researches on Higher Education, 12.

Wang, Yanqiu. (2006). On the Training of Social Responsibility of College Students. Journal of Beijing Youth Politics College, 03. 